http://dx.doi.org/10.4314/ajid.v7i2.1

\title{
CONTINUITIES IN THE HIV/AIDS POLICY DEBATE IN SOUTH AFRICA
}

\author{
Lincoln J. Fry \\ State Attorney's Office (retired), Florida's $15^{\text {th }}$ Judicial Circuit \\ Palm Beach County, Florida \\ E-mail: lincolnfry@bellsouth.net
}

\begin{abstract}
Wouters et al. (2010) critiqued the prospects of success for South Africa's new National Strategic Plan (NSP) for HIV/AIDS; they stressed the need to mobilize people living with HIV/AIDS and their communities in order to implement the comprehensive HIV/AIDS strategy. Utilizing the South African sample from the Fourth Round of the Afrobarometer survey, this paper identifies the factors which predicted respondent selection of HIV/AIDS as an important issue for the government to address. The identification of HIV/AIDS as an important governmental problem became the study's dependent variable. Other possible important factors were whether respondents had personal knowledge of HIV/AIDS, meaning they knew someone who died of AIDS, poverty, and their assessments of the way the government was handling the HIV/AIDS crisis. Respondent background and demographic characteristics were also included in a logistic regression analysis. The results identified three factors that predicted respondent choice of HIV/AIDS: race, especially being a Black South African, the choice of health as a governmental priority, and the rural-urban dimension. The conclusion was that HIV/AIDS, as opposed to health, should be the focus of campaigns designed to mobilize public support of comprehensive HIV/AIDS strategies in South Africa.
\end{abstract}

Key words: Knowledge of AIDS; Assessment of government handling of AIDS; National Strategic Plan for HIV/AIDS; Afrobarometer

\section{Introduction}

In a seminal paper, Caldwell, Orubuloye, and Caldwell (1992) pointed to what they called the under-reaction of those parts of sub-Saharan Africa most affected by the HIV/AIDS epidemic; this included both the public and private reaction to the seriousness of the HIV/AIDS phenomenon. One major implication of these studies was that ordinary citizens in sub-Saharan Africa were more concerned with basic issues like jobs and poverty, and did not want governmental resources diverted to HIV/AIDS related programs (Whiteside et al., 2002). AIDS had been diagnosed for the first time in two patients in South Africa; in 1983, Ras et al. (1983) and Sher (1989) reported that 166 cases of AIDS infection had been reported from 1982 through 1988, with a mortality rate of 59.2 percent. The question addressed here is how ordinary citizens in South Africa currently perceive the importance of HIV/AIDS vis-a-vis the South African national agenda. That issue is addressed in this paper by building upon earlier papers generated by the Afrobarometer Project, the source for the data used in this study.

The first of these papers asked the question, "How do ordinary people experience and understand the HIV/AIDS pandemic?" (Whiteside et al., 2002). Afrobarometer conducted country level surveys in 1999 and 2000. The study was concerned with the level of respondent awareness and contact with the epidemic, especially with the degree to which respondents recognized the increasing amount of death around them due to AIDS. A wide range of reported contact with AIDS related deaths was recorded at the country level, which was found to be 16 percent in South Africa. The next Round (2) of Afrobarometer surveys revealed some significant increases in public consciousness regarding HIV/AIDS, with South African respondents who identified HIV/AIDS as a national problem increasing to 26 percent in 2002, up from 13 percent in 2000. (Afrobarometer, 2004). By 2004, when Round 2.5 was conducted, almost one- third of South Africans ( 30 percent) cited AIDS as one of the three "most important problems facing the country that government ought to address," virtually the same as the 31 percent who noted the issues of crime and security. Only job creation outdistanced these two issues, selected by 77 percent of the respondents. (Afrobarometer, 2005). This shows that the focus on AIDS as a public problem had increased substantially, moving from less than 1 percent in 1999, to 13 percent in 2000, 26 percent in 2002, and now to 30 percent as measured in 2004 (Afrobarometer, 2006).

By the late 1980s and early 1990s, HIV/AIDS had become part of the national agenda. Wouters et al. (2010) have provided a systematic review of the literature on post-apartheid AIDS policy in South Africa, covering the various stages of AIDS policy development from 1994 to 2008. Their purpose was to evaluate the chances of success of the current National Strategic Plan (NSP) for South Africa, 2007-2011. Wouters et al pinpointed human resources shortages in health as the primary obstacle for increasing the scale of ART in the face of the massive epidemic and a weak health care system; the holistic policy context of the recent and earlier plans was not implemented. Civil society's response to this failure has been to ask for more treatment and to take the government to court to enforce the provision of ART drugs. This created a new process of policy making and implementation, what has been called "public policy by litigation".

The next important Afrobarometer paper was published by Justesen (2011). He concluded that over time HIV/AIDS in Africa has transformed from being mainly a health issue to being a major human and economic development issue, one with devastating 
http://dx.doi.org/10.4314/ajid.v7i2.1

effects on the lives of millions of Africans. Justesen also noted that in the African countries included in the Afrobarometer surveys it would be easy to conclude people who mention "AIDS" and those who mention "health" issues are essentially describing the same problem. Yet this would miss some important subtleties. For instance, we find that to the extent that people see the epidemic as meriting government action, they tend either to see it as an AIDS issue, or as a health issue, but not both: those people who mention health are less likely to cite "AIDS"; and national publics that collectively prioritize "health" are much less likely to prioritize "AIDS. This is an issue to be addressed in this paper's analysis section where the prioritization of HIV/AIDS and Health by South Africans are compared.

\section{Materials and Methods}

The data source used in this study, Afrobarometer, is a collaborative research effort currently produced by social scientists from 20 African countries. The Project's objectives are as follows: 1) to produce scientifically reliable data on public opinion in sub-Saharan Africa; 2) to strengthen institutional capacity for survey research in Africa ; and 3) to broadly disseminate and apply survey results. Begun in 1999, four multi-country rounds of the survey have been completed to this point in time. As is explained below, the country targeted here, South Africa, was included in all four waves; the last round available of country level surveys was conducted in 2008. The dates and number of countries included in the surveys were as follows: Round 1, from July 1999 through June 2001 in 12 countries; Round 2, from May 2002 through October 2003 in 16 countries; Round 3, from March 2005 through February 2006 in 18 countries; and Round 4, from March 2008 through June 2009. There was Afrobarometer South African survey, referred to as 2.5, which was conducted in 2004. A fifty Round is being completed , 2011-2013, but results are not available at this time The present paper is based on data collected in South Africa during Round 4.

The South African Survey: Interviews were completed with 2,400 citizens of South Africa, 18 years of age or older. These are face-to-face interviews and were conducted in eleven different languages. The sampling frame included all nine South African provinces, and the final sample supports estimates of the national population of all adults in South Africa that is accurate to within a margin of error of plus or minus 2 percentage points at a confidence level of 95 percent.

Sampling Procedures: The sampling procedures used in all of the Afrobarometer surveys are explained in detail in Bratton, Mattes and Gyimah-Boadi (2005). Data collection procedures were standardized for all 20 countries included in Round 4.

The Questionnaire: The survey uses the same questionnaire which contains identical or functionally equivalent items in all 20 of the current Afrobarometer countries. The interviewer asks the respondent a series of questions in a face-to-face situation and in a language of the respondent's choice.

Measures: The study's dependent variable is the selection of AIDS as an issue the government should address, and is measured by the following question: In your opinion, what are the most important problems facing this country that the government should address? This question was asked in the same form three times. As Justesen (2011) indicated, one advantage of the wording of the 'most important problem' (MIP) question is that respondents can only name up to three problems, which forces people to prioritize and select those problems they consider the most important. In this study, the importance of AIDS is coded as a dichotomous variable: If a respondent mentioned 'AIDS' as one of the three most important problems, the variable is coded as one (1), and if not, zero (0).

Independent Variables: The choice of health as an issue the government should address was created in the same manner as the choice of AIDS. Respondents that picked health as one of their three important problems government should address were coded as one (1) and if they did not pick health zero (0) was recorded. In order to capture the respondents personal knowledge of AIDS a dummy variable coded as one (1) yes or no (0) asked whether respondents knew people who have died from AIDS, including close friends or relatives. Two additional questions asked the respondent to rate how well or badly the Mbeki government handled combating HIV/AIDS and improving basic health services, and the field interviewers were asked to indicate whether a health clinic was available in the respondent's sampling unit.

Consistent with the approach Justesen (2011) utilized in his study, this research used a direct measure of poverty, which is based on people's lack of basic necessities (Mattes et al. 2003; Bratton et al. 2004; Bratton 2008). The questionnaire contains five questions concerning respondents' experience with lack of basic necessities. Specifically, respondents are asked how often during the past year, they or anyone in their family have gone without: a) enough food to eat, b) enough clean water for home use, c) medicines or medical treatment, d) enough fuel to cook food, and e) a cash income. Answers were recorded using a five-point scale from "never" to "always". These measures created a poverty index with a scale reliability coefficient of .832 (Cronback's Alpha).

A series of demographic variables were also included in the analysis, This included the rural-urban distinction, gender, age, race (coded 1 for Black African and 0 for all others), and education (coded on an 8 point range from zero to eight, with 0 equaling no education and 8 indicating college/university graduation). One item asked whether the respondent was employed.

The Analysis: Since the dependent variable is dichotomous, logistical regression was chosen to be the procedure to identify the variables that predict the choice of HIV/AIDS as a governmental priority. Simple frequency counts were used to display the 
http://dx.doi.org/10.4314/ajid.v7i2.1

sample's characteristics and the breakdowns of the responses to the HIV/AIDS and health questions. Simple cross-tabulation was used as the means to show the relationship between the choice of HIV/AIDS and Health as governmental priorities.

\section{Results}

The first issue was to identify the characteristics of the South African sample. Table 1 displays those results.

\section{Age}

18 through 29

30 thru 49

50 and over

\section{Gender}

Male

Female

Race

Black/African

White/European

Coloured/Mixed Race

South Asian (Indian, Pakistani, etc.)

East Asian (Chinese, Korean, Indonesian )

\section{Education}

No formal/informal schooling only

Some primary schooling

Primary school completed

Some secondary/high school

Completed secondary/high school

Post-secondary qualifications, not university

Some University

Completed University

missing

Residence

Urban

Rural

Table 1: Demographic Characteristics of the South African Sample $(\mathrm{N}=2,400)$

$\begin{array}{rr}814 & 34.3 \\ 1,076 & 45.3 \\ 485 & 20.4 \\ & \\ 1,200 & 50.0 \\ 1,200 & 50.0 \\ & \\ 1,523 & 63.5 \\ 390 & 16.2 \\ 356 & 14.8 \\ 125 & 5.2 \\ 6 & 0.3 \\ & \\ 110 & 5.6 \\ 216 & 9.1 \\ 194 & 8.2 \\ 778 & 32.7 \\ 684 & 28.8 \\ 277 & 11.7 \\ 58 & 2.4 \\ 60 & 2.5 \\ 23 & \\ & \\ 1,576 & 65.7 \\ 824 & 34.3\end{array}$

Table 1 shows that the sample was equally divided between the sexes; two thirds of the sample were Black Africans, 63.5 percent. The two largest educational attainment categories were "some secondary school, 32.7 percent, and completed secondary school, 28.8 percent. Two thirds of the sample were urban dwellers, 65.7 percent.

The next issue was to look at the sample breakdowns regarding the measures related to HIV/AIDS and the Health questions. Table 2 presents those findings.

Table 2 reveals that 487 respondents, 20.7 percent of the sample, indicated that HIV/AIDS was an important issue government should address. Two hundred and eighty five (285) respondents indicated that health was an important issue that government should address. Roughly 30 percent of the sample (29.9 percent) knew someone who died of AIDS. Table 2 showed that over half of the respondents indicated the government had handled combating HIV/AIDS either very or fairly badly (58.1 percent), and slightly over half (52.4 percent) responded that the government handled improving basic health services either fairly or very badly. The interviewers indicated that there was a health clinic in 27.4 percent of the respondents' reporting area As indicated above, logistical regression was chosen to answer the question regarding the identification of those factors that predict the choice of HIV/AIDS as a governmental priority. The results of that analysis are presented in Table 3.

Table 3 shows that three factors reached statistical significance in the logistic regression. Two of these were very powerful, race, being a Black African, and the surprising finding that the choice of health as a government priority were the strongest predictors. Both factors reached significance beyond the .000 level. Race had a Z score of 7.41 and the choice of health a $\mathrm{Z}$ score of -5.40 . The only other factor to reach significance in Table 3 was the rural-urban dimension, $\mathrm{p}=.04$, and a $\mathrm{z}$ score of -2.02 . Several factors fell just short of significance, both questions which asked about the way the government had handled combating HIV/AIDS and improved basic health services, both reported at the $\mathrm{p}=.06$ level. Also surprising was the fact that knowing 
http://dx.doi.org/10.4314/ajid.v7i2.1

someone who died of Aids did not reach significance, and neither did the Lived Poverty Index. Age, gender, education and employment were non-factors, as was the presence of a health clinic in the sampling unit.

Table 2: Breakdown of Study Measures related to HIV/AIDS and Health Questions.

Is HIV/AIDS an important issue government should address?

\begin{tabular}{lr} 
Yes & $487(20.7)$ \\
HIV/Aids Not selected & $1,868(79.3)$ \\
\multicolumn{1}{c}{ Is Health an important issue } & $285(12.1)$ \\
Yes & $2,070(87.9)$ \\
Health not selected & \\
Know Someone Who died of AIDS? & $635(29.9)$ \\
Yes & $1,488(70.1)$ \\
No & $749(32.1)$ \\
How Well Did the Government handle /Combat HIV/AIDS? & $606(26.0)$ \\
Very badly & $675(28.9)$ \\
Fairly badly & $305(13.1)$ \\
Fairly well & \\
Very well & \\
How well did the Government Handle Improving Basic Health \\
\multicolumn{1}{l}{ Services? } \\
Very badly & $556(23.7)$ \\
Fairly badly & $675(28.7)$ \\
Fairly well & $831(35.4)$ \\
Very well & $287(12.2)$ \\
Is there a health clinic in the reporting area? & \\
Yes & $640(27.4)$ \\
No & $1,700(72.6)$
\end{tabular}

Table 3: Logistic Regression: Choice of HIV/AIDS as a GOVERNMENTAL PRIORITY

Variable

Urban rural

Race

Health government priority

Health Clinic present

Gvt. Handled health services

Know Died of AIDS

Gvt. Handled HIV/AIDS

Age

Gender

Education

Employed

Lived Poverty Index

Constant

Number of observations $=1,904$

Pseudo R2 =. 074
Coefficient Standard Error

$-.27$

1.16

.134

.157

$-2.02$

7.41

7.41
5.40

$-0.35$

$-.05$

.348

.136

1.30

-0.35
1.89

1.50

$-1.89$

.131

.005

$-.72$

.88

.14

1.46

$\begin{array}{lrr}.118 & 1.46 & 0.15 \\ .014 & -0.17 & 0.86\end{array}$

$\begin{array}{lll}.477 & -3.75 & 0.000\end{array}$

$\mathrm{P} \quad>|\mathrm{z}|$

0.04

.000

0.000

0.73

0.06

0.13

.06

0.47

.39

0.89

0.15

The final issue to be addressed is the relationship between the choice of HIV/AIDS and health as a governmental priority. As mentioned above, Justensen (2011) had indicated it may seem that people are talking about the same thing, but he argued that they are not. He indicated that respondents that choose health are not likely to choose HIV/AIDS s governmental priorities. Even though the logistical regression analysis highlighted this factor, Table 4 takes an even closer look at the HIV/AIDS-health choice in this South African sample.

Table 4 revealed that only 10 of the 2,355 (.004 percent) of these South African respondents that had identified governmental priorities chose both HIV/AIDS and Health as issues government should address. Calculation of the chi-square statistic for Table 4 revealed that expected value for those picking both HIV/AIDS and Health was 58 respondents, accounting for the strength of the chi-square value in Table 4. 
http://dx.doi.org/10.4314/ajid.v7i2.1

Table 4: Choice of HIV/AIDS and or Health as Governmental Priorities

$\begin{array}{cccc}\text { Health Priority } & \text { NO } & \text { YES } & \text { HIV/AIDS Priority } \\ \text { NO } & & & \text { TOTAL } \\ \text { Yes } & 1,593(77.0) & 477(23.0) & 2,070 \\ & 275(96.5) & 10(3.5) & 285 \\ \text { TOTAL } & 1,858 & 487 & 2,355 \\ \text { Yate's chi-square= 57.1 } & \mathrm{P}=.000 & & \end{array}$

\section{Discussion}

The results presented here do not bode well for the future of HIV/AIDS as an important governmental concern in South Africa, especially when compared to other national level problems like employment, poverty and an adequate food supply. The multiple issues that Wouters et al. (2010) identified as impediments to the successful implementation of a comprehensive HIV/AIDS program will continue to hinder the effectiveness of the policies designed to attack the epidemic. Wouters et al. suggested that placing HIV/AIDS programs under the umbrella of public health had been a mistake, one that was continued under the new Strategic Plan. Not only is the public health service overburdened in South Africa, the system suffers from professional brain drain, with shortages of qualified medical personnel a major impediment to the provision of services. At a time when there is a global financial crisis, the costs of HIV/AIDS treatment continues to rise, yet mathematical models which will generate even higher costs to implement universal HIV testing continue to be produced and favorably reviewed as the possible wave of the future. (Granich et al, 2008).

One way to begin to discuss the results presented above is to note the independent variables that were expected to but did not reach significance in the logistic regression. The first is knowledge of AIDS, knowing someone who died of AIDS as well as the poverty measure used by Justesen (2011) and this study. Other than race and the choice of health as a governmental priority, the only other independent variable that reached significance was the urban-rural dimension.

The finding that being a Black African was the strongest predictor of the choice of HIV/AIDS as a governmental concern was to be expected. Based on what this study reveals about the HIV/AIDS versus health issue, there is a clear message that speaks to the need to address the epidemic per se as opposed to including it under the public health agenda. One major emphasis in the literature has been on the requirement to adopt more expansive Public Health approaches to address HIV/AIDS (De Cock et al. 2002). De Cock et al argued that HIV/AIDS has been treated differently from other sexually transmitted or lethal infectious diseases, despite being the leading cause of death in Africa. The results presented here suggest the call to take a more aggressive public health stance toward HIV/AIDS is misguided. The need is for prevention and educational efforts to focus solely on the scope and consequences of the epidemic for Black South Africans, and all other South Africans as well.

\section{Conclusion}

The question was how to mobilize people living with HIV/AIDS and their communities in order to implement the comprehensive HIV/AIDS strategy in South Africa. This paper attempted to identify the factors that predicted respondent selection of HIV/AIDS as an important issue for the government to address. The study identified three factors which predicted HIV/AIDS as a concern of government: race (being a black South African), the choice of health as a governmental concern, and the urban-rural dimension. Some surprising findings were found in the fact that this study did not find certain factors predictive of the choice of HIV/AIDS as a governmental concern. These factors included knowing someone who died of AIDS, and poverty. The surprising finding was that the choice of health was such a strong predictor of not selecting HIV/AIDS. The suggestion is that the placement of HIV/AIDS programs under the health rubric has had a negative impact on promoting the importance of HIV/AIDS and the need is to promote the importance of HIV/AIDS to all South Africans as a major concern of government. The conclusion was that campaigns are needed that are solely designed to mobilize public support for HIV/AIDS as an important issue in the national agenda of South Africa.

\section{References}

1 Afrobarometer (2004) Public Opinion and HIV/AIDS: Facing UP to the Future. Briefing Paper No. 12

2 Afrobarometer (2005) AIDS and Public Opinion in South Africa. Afrobarometer Briefing Paper No. 14

3 Afrobarometer (2006) The Public Agenda: Change and Stability in South African's ratings of National Priorities.

Afrobarometer Briefing Paper no. 43

4 Bratton, Michael, Robert Mattes and E. Gyimah-Boadi (2004). Public Opinion, Democracy, and Market Reform in Africa. Cambridge: Cambridge University Press. 
http://dx.doi.org/10.4314/ajid.v7i2.1

5 Bratton, Michael, Robert Mattes and E. Gyimah-Boadi (2008). 'Poor people and democratic citizenship in Africa'. In Anirudh Krishna, ed., Poverty, Participation, and Democracy: A Global Perspective.

6 Caldwell, J. \& Orubuloye,I. \& Caldwell P (1992) Underreaction to AIDS in Sub-Saharan Africa. Science and Medicine, 34, 1169-1182

7 DeCock,k.,Mbori-Ngacha, D., and Marum,E (2002) Shadow on the Continent: Public Health and HIV/AIDS in Africa in the $21^{\text {st }}$ Cen5tury. The Lancet 360,6772

8 Granich, R., Gilks, C., Dye, C. ,Decock,K. ,and Williams, B.(2009) Universal Voluntary HIV Testing with immediate antiretroviral therapy as a strategy for elimination of HIFV transmission: a mathematical model. The Lancet 373 available at http://www.the lancet.com/journals/lancet/article/PIISo140-6736

9 Justesen, M. (2011) Too Poor to Care? The Salience of AIDS in Africa. Afrobarometer Working Paper no. 133

10 Mattes, R., Bratton, M. \& Davids, Y. (2003) Poverty, Survival, and Democracy in Southern Africa, Afrobarometer Working Paper N

11 Ras, G., Simon, I. Anderson, R., Prozesky, O. \& Hamersma, T. (1983) Acquired Immunodeficiency Syndrome: a report of 2 South African cases. South African Medical Journal. 64: 140-142

12 Sher, R (1989) HIV infection in South Africa, 1982-1988-a review .South African Medical Journal76-314-318

13 Whiteside, A., Mattes,R., Willan, S. \& Manning, R. (2002). 'Examining HIV/AIDS in Southern African through the eyes of ordinary Southern Africans'.Afrobarometer Working Paper No. 21.

14 Wouters, E., van Rensburg, H. \& Meulemans, H (2010) The national Strategic Plan of South Africa: what are the prospects of success after repeated failure of previous AIDS policy? Health Policy and Planning 25: 171-185 